\title{
Comparison of two questionnaires which measure the health-related quality of life of idiopathic pulmonary fibrosis patients
}

C.S. Zimmermann ${ }^{1}$, C.R.F. Carvalho ${ }^{1}$, K.R. Silveira ${ }^{1}$, W.P.S. Yamaguti ${ }^{1}$, E.V. Moderno ${ }^{1}$, J.M. Salge ${ }^{2}$ R.A. Kairalla ${ }^{2}$ and C.R.R. Carvalho ${ }^{2}$
${ }^{1}$ Departamento de Fisioterapia, Fonoaudiologia e Terapia Ocupacional, ${ }^{2}$ Disciplina de Pneumologia, Instituto do Coração, Faculdade de Medicina, Universidade de São Paulo, São Paulo, SP, Brasil

\section{Correspondence}

C.R.R. Carvalho

Rua Dr. Sampaio Viana, 509, Apto. 21 04004-002 São Paulo, SP

Brasil

Fax: +55-11-3885-7036

E-mail: crrcarvalho@uol.com.br and

crrcarvalho@hcnet.usp.br

Research supported by FAPESP

and LIM HC-FMUSP.

$\ldots \ldots \ldots \ldots \ldots \ldots$

Received January 18, 2006 Accepted October 31, 2006

\begin{abstract}
The objective of the present study was to determine if there is a healthrelated quality of life (HRQL) instrument, generic or specific, that better represents functional capacity dysfunction in idiopathic pulmonary fibrosis (IPF) patients. HRQL was evaluated in 20 IPF patients using generic and specific questionnaires (Medical Outcomes Short Form 36 (SF-36) and Saint George's Respiratory Questionnaire (SGRQ), respectively). Functional status was evaluated by pulmonary function tests, 6-min walking distance test (6MWDT) and dyspnea indexes (baseline dyspnea index) at rest and after exercise (modified Borg scale). There was a restrictive pattern with impairment of diffusion capacity (total lung capacity, TLC $=71.5 \pm 15.6 \%$, forced vital capacity $=70.4 \pm 19.4 \%$, and carbon monoxide diffusing capacity $=41.5 \pm 16.2 \%$ of predicted value), a reduction in exercise capacity $(6 \mathrm{MWDT}=435.6 \pm 95.5 \mathrm{~m})$ and an increase of perceived dyspnea score at rest and during exercise ( $6 \pm 2.5$ and $7.1 \pm 1.3$, respectively). Both questionnaires presented correlation with some functional parameters (TLC, forced expiratory volume in $1 \mathrm{~s}$ and carbon monoxide diffusing capacity) and the best correlation was with TLC. Almost all of the SGRQ domains presented a strong correlation with functional status, while in SF-36 only physical function and vitality presented a good correlation with functional status. Dyspnea index at rest and 6MWDT also presented a good correlation with HRQL. Our results suggest that a specific instead of a generic questionnaire is a more appropriate instrument for HRQL evaluation in IPF patients and that TLC is the functional parameter showing best correlation with HRQL.
\end{abstract}

Key words

- Idiopathic pulmonary

fibrosis

- Health-related quality of life

- Functional status 


\section{Introduction}

Idiopathic pulmonary fibrosis (IPF) is a distinctive type of chronic fibrosing interstitial pneumonia of unknown cause associated with a surgical lung biopsy showing a histological pattern of usual interstitial pneumonia (1). Usually, the age at onset is more than 50 years and IPF is slightly more common in males. Clinically, it is characterized by dyspnea, nonproductive cough, reduced lung volumes, and abnormal gas exchange. Constitutional symptoms such as weight loss, malaise, and fatigue may also be present (2, 3 ). Since treatment remains unsatisfactory, IPF patients present a progressive course that results in severe disability and death in the majority of cases. Clinical deterioration is the most frequent result of disease progression, with almost half the deaths being due to progressive respiratory failure (3-5). Thus, prognosis is poor with a median length of survival from time of diagnosis of less than four years (1,3-6). During the clinical course of the disease, patients invariably become severely limited in their activities and dependent on supplemental oxygen (3).

An international consensus for the diagnosis of IPF (1) has been recently published, but controversy persists in terms of treatment and factors affecting prognosis (7-9). It seems that pulmonary function tests continue to be the best parameter to assess response to therapy, prognosis and survival in IPF patients $(1,10)$. Erbes and associates (11) also showed that total lung capacity (TLC) alone or in combination with vital capacity holds greater prognostic value than diffusing capacity at rest or during exercise.

Probably, more important than how long the patient survives or even the results of pulmonary function tests, is the health status or quality of life of these patients. Healthrelated quality of life (HRQL) assesses the influence of disease on physical, emotional, and social functioning and is an important parameter for measuring the impact and pro- gression of chronic diseases. During the last 25 years, HRQL questionnaires have been applied to quantify average changes in health and the effects on patient daily life in several types of chronic lung diseases (12-14).

There are few studies evaluating HRQL in IPF patients (3) and even those have not established which sort of questionnaire should be used, and its relationship with functional measurements. Two kinds of questionnaires have been used: generic and disease specific. Generic instruments have the advantage of having been thoroughly tested in several clinical settings and populations. There is evidence suggesting that diseasespecific respiratory questionnaires are unnecessary for measuring HRQL in IPF patients $(15,16)$. In contrast, Chang and associates (17) suggest that nonspecific as well as specific disease questionnaires are sensitive and can be applied to IPF patients.

The main goal of the present study was to determine if there is an HRQL instrument, generic or specific, that better represents functional capacity dysfunction in IPF patients.

\section{Material and Methods}

\section{Patients}

All patients with documented IPF, identified through clinical records, who attended the Interstitial Lung Diseases Group as outpatients at Hospital das Clínicas, University of São Paulo (São Paulo, SP, Brazil) over a period of 6 months, were invited to participate in the study. Twenty-four eligible patients were identified and 22 participated after providing written informed consent. Two of them presented significant clinical deterioration before finishing the protocol and were excluded. A group of 20 patients completed all the tests. There were 12 men and 8 women, with a mean ( \pm SD) age of $61.4 \pm 10.5$ years, and $3.1 \pm 1.8$ years of presence of the disease since the diagnosis 
of IPF. None of them presented interstitial lung disease associated with connective tissue disease, significant occupational or environmental exposure, active coronary artery disease or other illnesses precluding performance of the 6-min walking distance test (6MWDT). IPF diagnosis was based on clinical, functional and radiological findings (1). An open-chest lung biopsy was performed in 18 patients and bronchoscopic evaluation (bronchoalveolar lavage and transbronchial biopsy) in 1, and evaluation based on typical clinical and high-resolution CT findings was performed in another one (1). The following criteria were considered for the diagnosis of IPF: abnormal pulmonary function studies showing evidence of pulmonary restriction (reduced TLC/forced vital capacity (FVC) with a normal or increased forced expiratory volume in $1 \mathrm{~s}$, $\mathrm{FEV}_{1} / \mathrm{FVC}$ ratio) and/or impaired gas exchange, increased alveolar-arterial $\mathrm{O}_{2}$ gradient with rest or exercise, or decreased diffusing lung capacity for carbon monoxide $\left(\mathrm{DL}_{\mathrm{CO}}\right)(1)$.

When the protocol started, 11 patients were taking intravenous steroids (pulse therapy with $1 \mathrm{~g}$ methyl-prednisolone per week) and the others were taking only $1 \mathrm{mg}$ colchicine per day. Five patients were under oxygen supplementation $24 \mathrm{~h}$ /day.

\section{Study design}

The study was conducted on two nonconsecutive days no longer than 15 days apart. On the first day, patients answered two HRQL questionnaires, a generic one (Medical Outcomes Short Form 36 (SF-36)) (18) and a respiratory disease-specific instrument (Saint George's Respiratory Questionnaire, SGRQ) (19), and the baseline dyspnea index (BDI) (20). Next, a 6MWDT was performed and a modified Borg scale was applied (21). On the second day, another 6MWDT followed by the modified Borg scale was performed. A complete lung func- tion test including $\mathrm{DL}_{\mathrm{CO}}$ was performed within 2 months of answering the questionnaires.

\section{Health-related quality of life}

Medical Outcomes Short Form 36. The SF-36 is a generic HRQL instrument which has been used to assess quality of life in a variety of chronic respiratory conditions including chronic obstructive pulmonary disease, asthma and IPF $(16,18,22)$. The SF-36 version validated for the Portuguese language was used (23). The questionnaire covers nine concepts: physical functioning, physical role, pain index, general health perceptions, vitality, social functioning, emotional role, mental health index, and health transition. We did not evaluate the health transition component, which deals with changes in the health status during the previous 12 months. Each dimension is scored separately on a 0 to 100 scale, in which higher scores correspond to a better quality of life.

Saint George's Respiratory Questionnaire. The SGRQ is a respiratory-specific HRQL instrument developed for patients with chronic obstructive pulmonary disease. Its validity, reproducibility, and response to change over time have been demonstrated in patients with asthma, bronchiectasis and IPF $(17,10,24)$. The questionnaire has three components: symptoms, which measures respiratory symptoms, activities, which measures impairment of mobility or physical activity, and impact, which measures the psychosocial impact of disease. Scores for these components and the summary score are on a 100point scale, which is opposite in direction to the SF-36. Higher scores correspond to worse health-related quality of life.

\section{Dyspnea analysis}

Baseline dyspnea index. The BDI comprises three subscales which are used to 
assess the severity of breathlessness: 1) the magnitude of effort needed to produce dyspnea, 2) the magnitude of the task needed to produce dyspnea, and 3) the degree of functional impairment due to dyspnea (20). Dyspnea is graded from zero to 4 , and the lower the number the greater the severity of the dyspnea. Each subscale score is summed to provide a total score of 0 to 12 .

\section{Six-minute walking distance test}

The test was performed in a 36-m long corridor. This test has been shown to be a reliable, valid and safe method of assessing functional status in both patients with chronic obstructive pulmonary disease and congestive heart failure $(25,26)$. Patients remained sitting for at least $10 \mathrm{~min}$ before the test. Before and after the test, heart rate, oxygen saturation, blood pressure, and modified Borg scale were measured. During the test, we did not use any encouragement phrases. Patients were allowed to stop and restart during the 6 $\mathrm{min}$ of the test, if necessary, and were allowed to use supplemental oxygen at the same inspired concentration normally used for their daily activities. The test was performed on two non-consecutive days to account for a learning effect and the best result was considered (27). After completing the walk, patients rated the amount of dyspnea experienced during the test on a modified Borg scale (21).

\section{Pulmonary function tests}

All pulmonary function tests were performed using Collins GS II equipment (Louisville, CO, USA), including a constant volume body plethysmograph. Static lung volumes and their subdivisions, vital capacity, TLC, residual volume were measured, and the results were reported as percentage of predicted values calculated according to gender, height, and age using Goldman reference equations of normality (28). $\mathrm{FEV}_{1}$, dy- namic lung volumes and maximal expiratory flows were measured with a volume displacement spirometer according to ATS technical recommendations (29), based on acceptability and reproducibility criteria. The results are reported as the best curve obtained in three maneuvers and presented as percentage of the value predicted by Knudson and co-workers (30). $\mathrm{DL}_{\mathrm{CO}}$ was measured by the single-breath method (29). Values are reported as percentage of the value predicted by Gaensler and Smith (31).

\section{Statistical analysis}

Correlation between quality of life scores and pulmonary function tests, 6MWDT, and BDI was evaluated by Pearson's coefficient. The Sigma Stat version 2.03 software package (San Jose, CA, USA) was used for statistical analysis, with the level of significance set at $\mathrm{P}<0.05$.

\section{Results}

The demographic and functional characteristics of the patients are summarized in Table 1 . Twenty patients performed all evaluations and presented, on average, a moderate reduction in lung volumes (in percentage of predicted value): TLC: $71.5 \pm 15.6 \%$, FVC: $70.4 \pm 19.4 \%$, and $\mathrm{FEV}_{1}: 77.3 \pm 21.3 \%$. Two patients presented a percent predicted residual volume over 100\%; however, all other pulmonary function parameters suggested a restrictive pattern. Reduction in $\mathrm{DL}_{\mathrm{CO}}$ was the main alteration in the pulmonary function tests $(41.5 \pm 16.2 \%$ of predicted). Patients presented on average impairment of exercise capacity (6MWDT average of $435.6 \mathrm{~m}$ ) and results ranged from no limitation $(648 \mathrm{~m})$ to severe limitation (272 m; Table 1). The values of the resting dyspnea index determined by the BDI scale were compatible with some limitation $(6 \pm$ $2.5)$ and the total score obtained was equally distributed among functional impairment (2.1 
$\pm 1.1)$, magnitude of task $(2.1 \pm 1)$ and magnitude of effort $(1.7 \pm 0.75$; Tables 1 and 2). Exertion dyspnea (modified Borg scale) also presented values compatible with limitation $(7.1 \pm 1.3$; Table 1$)$.

Table 2 shows the HRQL scores determined by specific (SGRQ) and generic (SF36) questionnaires. Both instruments revealed a reduction in HRQL (SGRQ $=48.4$ \pm 17.9 and $\mathrm{SF}-36=55.7 \pm 28.4$ ). The most affected domain in the SGRQ was activity (higher value, $62.4 \pm 19$; Table 2). In the SF36 , the mental health domain was the least affected (higher value) while physical function, vitality and emotional aspect were the most affected (lower values, $46 \pm 18.3,49.2 \pm$ 24.3 , and $46.6 \pm 39.5$, respectively; Table 2).

Total SGRQ domains presented a good correlation ( $r>0.5$ ) with TLC (0.66), FEV $(0.57)$, and $\mathrm{DL}_{\mathrm{CO}}(0.47)$ as well as $6 \mathrm{MWDT}$ (0.72) and rest dyspnea index (0.72; Table $3)$. Good correlations were also observed between lung function, exercise capacity and rest dyspnea index and all SGRQ domains, except the symptom domain that showed correlation only with residual volume. When HRQL was evaluated by the SF-36, only the physical function and vitality domains presented a good correlation with $\mathrm{FEV}_{1}(0.50$ and 0.48 , respectively) and TLC (0.61 and 0.51 , respectively), and only vitality correlated with $\mathrm{DL}_{\mathrm{CO}}(0.54$; Table 3). The physical function and vitality domains also presented a good correlation with 6MWDT $(0.69$ and 0.50 , respectively) and the physical function, vitality and social function domains correlated with BDI $(0.73,0.58$, and 0.47 , respectively). Interestingly, 6MWDT presented a good correlation with $\mathrm{FEV}_{1}(0.56)$, TLC (0.65) and $\mathrm{DL}_{\mathrm{CO}}(0.54)$, whereas dyspnea correlated only with $\mathrm{FEV}_{1}(0.51)$ and $\mathrm{DL}_{\mathrm{CO}}(0.45)$.

\section{Discussion}

The present results showed that generic (SF-36) and specific (SGRQ) questionnaires revealed a similar decrease in $\mathrm{HRQL}$ aspects of IPF patients. However, the SGRQ seems to evaluate HRQL more appropriately in our population since almost all of its domains

Table 1. Clinical and physiological features of idiopathic pulmonary fibrosis patients.

\begin{tabular}{lrc}
\hline & Mean \pm SD & Range \\
\hline Age (years) & $61.46 \pm 10.52$ & \\
Lung function values & & \\
FVC (\% of predicted) & $70.4 \pm 19.4$ & $40-113$ \\
FEV $1 \%$ of predicted) & $77.3 \pm 21.3$ & $42-125$ \\
TLC (\% of predicted) & $71.5 \pm 15.6$ & $45-102$ \\
VC (\% of predicted) & $69.8 \pm 20.2$ & $37-110$ \\
DLCo (\% of predicted) & $41.5 \pm 16.2$ & $10-74$ \\
Functional scores & & \\
6MWDT (m) & $435.6 \pm 95.5$ & $272-648$ \\
SaO $(\%)$ & $95.5 \pm 2.6$ & $89-98$ \\
Dyspnea & $6 \pm 2.5$ & $2-11$ \\
BDI & $7.1 \pm 1.3$ & $3-10$ \\
Borg scale & & \\
\hline
\end{tabular}

Data are reported as means \pm SD and range for 12 male and 8 female patients. FVC $=$ forced vital capacity, $\mathrm{FEV}_{1}=$ forced expiratory volume in $1 \mathrm{~s}$; $\mathrm{TLC}=$ total lung capacity; VC = vital capacity, $\mathrm{DL}_{\mathrm{CO}}$ = $\mathrm{CO}$ diffusing capacity; $6 \mathrm{MWDT}=6$-min walking distance test; $\mathrm{SaO}_{2}=$ oxygen saturation of hemoglobin; $\mathrm{BDI}=$ baseline dyspnea index

Table 2. Health-related quality of life scores.

\begin{tabular}{ll}
\hline SGRQ & \\
Symptom & $46.4 \pm 20.3$ \\
Activity & $62.4 \pm 19$ \\
Impact & $43.6 \pm 20.9$ \\
Total score & $48.4 \pm 17.9$ \\
SF-36 & \\
$\quad$ Physical function & $46 \pm 18.3$ \\
Body pain & $60.6 \pm 31.9$ \\
Physical role & $57.5 \pm 39.8$ \\
General health & $53.7 \pm 24.1$ \\
Vitality & $49.2 \pm 24.3$ \\
Social function & $56.9 \pm 32.2$ \\
Emotional aspects & $46.6 \pm 39.5$ \\
Mental health & $66.8 \pm 17$ \\
BDI & \\
Functional impairment & $2.1 \pm 1.1$ \\
Magnitude of task & $2.1 \pm 1$ \\
Magnitude of effort & $1.7 \pm 0.75$ \\
Total score & $6 \pm 2.5$
\end{tabular}

Data are reported as means \pm SD. SGRQ $=$ Saint George's Respiratory Questionnaire; SF-36 = Medical Outcomes Short Form 36 questionnaire; BDI = baseline dyspnea index. 
presented a good relationship with lung function, exercise capacity and dyspnea. Besides, TLC presented a strong relationship with both HRQL instruments and seems to be the functional parameter that best represents HRQL aspects.

IPF is a disease causing progressive breathlessness and commonly resulting in respiratory failure and death $(3,32)$. IPF treatment has been focused on avoiding disease progression and improving survival. However, improving quality of life is extremely important for many patients and should perhaps be a more realistic goal (26). Over the last few years, some studies have examined HRQL in patients with IPF (15-17) and, independent of subject inclusion criteria and instrument used, all studies observed significant impairment in IPF patients' HRQL and quality of life relative to the general population.

Two types of HRQL questionnaires are widely available: generic and disease-specific instruments. Disease-specific instruments are tailored to patients with a certain disease or condition and are likely to be more sensitive to changes in a patient's status than generic instruments (33). SGRQ and the Chronic Respiratory Questionnaire (CRQ) were developed specifically for patients with chronic airflow obstruction and contain three domains: impact, activities and symptoms $(24,34)$. SF-36 is a general HRQL instrument but has already been extensively validated for respiratory and non-respiratory conditions (18). Few studies have evaluated HRQL in patients with IPF and five different instruments have been used, two disease-specific ones developed for patients with obstructive lung disease (CRQ and SGRQ) $(16,17,34)$, two generic HRQL instruments (SF-36 and Quality of Well Being) $(16,17,34,35)$, and a generic quality of life instrument (WHOQOOL-100) $(15,36)$. Despite these studies, there are still some concerns about the availability of a better instrument to evaluate patients' HRQL (33).

In general, validation of these instruments is based on testing an a priori hypothesis that a worse quality of life score should

Table 3. Correlations between health-related quality of life scores and functional status.

\begin{tabular}{|c|c|c|c|c|c|c|}
\hline & $\begin{array}{c}\text { TLC } \\
\text { (\% predicted) }\end{array}$ & $\begin{array}{c}\mathrm{FEV}_{1} \\
\text { (\% } \text { predicted) }\end{array}$ & $\begin{array}{c}\text { VC } \\
\text { (\% predicted) }\end{array}$ & $\begin{array}{c}\mathrm{DL} \text { co } \\
\text { (\% predicted) }\end{array}$ & $\begin{array}{l}\text { 6MWDT } \\
(\mathrm{m})\end{array}$ & BDI \\
\hline \multicolumn{7}{|l|}{ SGRQ } \\
\hline Symptoms & 0.37 & 0.08 & 0.14 & 0.41 & 0.41 & $0.62^{*}$ \\
\hline Activities & $0.65^{\star}$ & $0.57^{*}$ & $0.54^{*}$ & 0.32 & $0.72^{*}$ & $0.75^{\star}$ \\
\hline Impact & $0.58^{*}$ & $0.52^{*}$ & $0.61^{*}$ & 0.39 & $0.63^{*}$ & $0.63^{*}$ \\
\hline Total & $0.66^{*}$ & $0.57^{*}$ & $0.56^{*}$ & $0.47^{\star}$ & $0.72^{*}$ & $0.72^{*}$ \\
\hline \multicolumn{7}{|l|}{ SF-36 } \\
\hline Physical function & $0.61^{*}$ & $0.50^{*}$ & $0.54^{*}$ & 0.47 & $0.69^{*}$ & $0.73^{+}$ \\
\hline Body pain & 0.27 & 0.28 & 0.28 & 0.00 & 0.28 & 0.20 \\
\hline Physical role & $0.43^{*}$ & 0.20 & 0.34 & 0.13 & 0.37 & 0.30 \\
\hline General health & $0.68^{*}$ & 0.10 & 0.13 & 0.17 & 0.27 & $0.52^{*}$ \\
\hline Vitality & $0.51^{*}$ & $0.48^{*}$ & $0.57^{*}$ & $0.54^{*}$ & $0.50^{*}$ & $0.58^{*}$ \\
\hline Social function & 0.47 & 0.23 & 0.27 & 0.36 & 0.34 & $0.47^{*}$ \\
\hline Emotional aspects & 0.32 & 0.22 & 0.28 & 0.25 & 0.31 & 0.24 \\
\hline Mental health & 0.13 & 0.04 & 0.04 & 0.16 & 0.00 & 0.06 \\
\hline BDI & $0.51^{*}$ & $0.51^{*}$ & 0.36 & $0.45^{\star}$ & $0.72^{*}$ & - \\
\hline 6MWDT & $0.65^{\star}$ & $0.56^{*}$ & $0.53^{*}$ & $0.54^{*}$ & - & $0.72^{*}$ \\
\hline
\end{tabular}


correlate with more severe physiologic impairment in clinical and exercise tests. Since there is no reference "gold standard" for the psychological construct HRQL, clinical parameters must be used as reference. Chang et al. (17) first evaluated HRQL in patients with interstitial lung diseases (IPF, sarcoidosis, hypersensitivity pneumonitis, and asbestosis) using four distinct questionnaires and only the SF-36 and SGRQ tools presented a relationship (from weak to moderate) with pulmonary function, 6MWDT and dyspnea score. In addition, SGRQ presented a better (moderate) relationship with all functional parameters than SF-36. Martinez et al. (16) evaluated quality of life specifically in IPF patients using only SF-36 and showed that only some aspects of the questionnaire (physical and social functioning, general health and vitality) presented a good relationship with dyspnea score. de Vries et al. (36) observed that WHOQOOL-100 presented a weak relationship with pulmonary function in IPF patients.

Taken together, these studies show that generic and specific questionnaires can evaluate HRQL in patients with IPF; however, their validity remains poorly known since many questionnaires have been used and few studies have tested their associations with clinical and functional parameters (33). Our study is the first to evaluate specific (SGRQ) and generic (SF-36) questionnaires regarding pulmonary function, exercise capacity and dyspnea specifically in IPF patients. Our results show that some domains of SF-36 (physical functioning, physical role and vitality) presented a moderate to good relationship with clinical parameters, whereas all SGRQ domains presented a good relationship with clinical parameters.

In contrast to previous results, we observed a good relationship between clinical and HRQL parameters. It is possible that the age of our patients and their advanced disease stage (with some of them receiving oxygen supplementation) could explain the better relationship observed between clinical aspects and HRQL. If this is true, it supports the fact that a specific questionnaire could be more adequate to assess patient HRQL and their clinical evaluation.

Static lung volumes are typically reduced in patients with IPF, whose prognosis has been mostly related to pulmonary function $(37,38)$. On this basis, pulmonary volumes should be the most important parameters used in HRQL validation. However, at present there are only three studies in which correlations between lung functions and HRQL were calculated (13-15). In general, the results of lung function testing correlate with HRQL scores in patients with interstitial pulmonary fibrosis, but many of these correlations are weak and not statistically significant. Besides, only two studies specifically evaluated IPF patients $(15,16)$ and each study reported the results of only some pulmonary function parameters, impairing comparison between their results and ours.

In contrast to previous results, our study showed a moderate to good relationship between HRQL and TLC, FEV ${ }_{1}$, and $\mathrm{DL}_{\mathrm{CO}}$. Interestingly, some studies have shown that prognosis is poorer in IPF patients with a reduction in TLC $(8,11,39)$. Erbes et al. (11) observed a decreased survival rate in IPF patients with a pre-therapy TLC of less than $78 \%$ of the predicted value. Besides, a combined reduction in vital capaciy and TLC was associated with a $46 \%$ reduction in 5year survival rates (7). These results agreed with previous data reported by Schwartz et al. (9) who observed an association between higher FVC and TLC and improved survival rates. Another study reported that IPF patients with a TLC lower than $60 \%$ of the predicted value are less responsive to new medication (prednisone and cyclophosphamide) than patients with TLC $>80 \%$ (8). These results suggest that TLC can be a lung function parameter that better represents the impact of the disease on IPF patients and might support our findings. 
In a very recent investigation, Nishiyama et al. (40) studied 41 IPF patients and showed that BDI and TLC were significantly correlated with total SGRQ score. However, the BDI score was the only factor significantly contributing to the total SGRQ score. Although these results appear to differ from those obtained in our study, they should be evaluated with caution since SGRQ was related to TLC in liters instead of percent predicted as shown in the present study. In our study, TLC measured in liters was not related to SGRQ. It is possible that lung volumes measured in liters do not represent the real effect of the disease on each patient. Besides, in our study dyspnea also presented a good relationship with SGRQ.

In conclusion, our results show that a specific (SGRQ) rather than a generic (SF36) questionnaire is a more appropriated instrument to evaluate HRQL in IPF patients. Our data also suggest that TLC presented a strong relationship with HRQL in the studied population.

\section{References}

1. American Thoracic Society/European Respiratory Society International Multidisciplinary Consensus Classification of the Idiopathic Interstitial Pneumonias. This joint statement of the American Thoracic Society (ATS), and the European Respiratory Society (ERS) was adopted by the ATS board of directors, June 2001 and by the ERS Executive Committee, June 2001. Am J Respir Crit Care Med 2002; 165: 277-304.

2. Katzenstein AL, Myers JL. Idiopathic pulmonary fibrosis: clinical relevance of pathologic classification. Am J Respir Crit Care Med 1998; 157: 1301-1315.

3. American Thoracic Society. Idiopathic pulmonary fibrosis: diagnosis and treatment. International consensus statement. American Thoracic Society (ATS), and the European Respiratory Society (ERS). Am J Respir Crit Care Med 2000; 161: 646-664.

4. Baughman RP, Lower EE. Use of intermittent, intravenous cyclophosphamide for idiopathic pulmonary fibrosis. Chest 1992; 102: 1090-1094.

5. Xaubet A, Agusti C, Luburich P, Roca J, Ayuso MC, Marrades RM, et al. Is it necessary to treat all patients with idiopathic pulmonary fibrosis? Sarcoidosis Vasc Diffuse Lung Dis 2001; 18: 289-295.

6. Raghu G, Mageto YN, Lockhart D, Schmidt RA, Wood DE, Godwin JD. The accuracy of the clinical diagnosis of new-onset idiopathic pulmonary fibrosis and other interstitial lung disease: A prospective study. Chest 1999; 116: 1168-1174.

7. Jezek V, Fucik J, Michaljanic A, Jezkova L. The prognostic significance of functional tests in cryptogenic fibrosing alveolitis. Bull Eur Physiopathol Respir 1980; 16: 711-720.

8. Johnson MA, Kwan S, Snell NJ, Nunn AJ, Darbyshire JH, TurnerWarwick M. Randomized controlled trial comparing prednisolone alone with cyclophosphamide and low dose prednisolone in combination in cryptogenic fibrosing alveolitis. Thorax 1989; 44: 280-288.

9. Schwartz DA, Helmers RA, Galvin JR, Van Fossen DS, Frees KL, Dayton CS, et al. Determinants of survival in idiopathic pulmonary fibrosis. Am J Respir Crit Care Med 1994; 149: 450-454.

10. Kirtland $\mathrm{SH}$, Winterbauer RH. Pulmonary function tests and idiopathic pulmonary fibrosis. Simple may be better. Chest 1997; 111: 7-8.

11. Erbes $R$, Schaberg $T$, Loddenkemper R. Lung function tests in patients with idiopathic pulmonary fibrosis. Are they helpful for pre- dicting outcome? Chest 1997; 111: 51-57.

12. Harrison BD. Psychosocial aspects of asthma in adults. Thorax 1998; 53: 519-525.

13. Maille AR, Kaptein AA, de Haes JC, Everaerd WT. Assessing quality of life in chronic non-specific lung disease - a review of empirical studies published between 1980 and 1994. Qual Life Res 1996; 5: 287-301.

14. Drent M, Wirnsberger RM, Breteler MH, Kock LM, de Vries J, Wouters EF. Quality of life and depressive symptoms in patients suffering from sarcoidosis. Sarcoidosis Vasc Diffuse Lung Dis 1998; 15: $59-66$.

15. de Vries J, Seebregts A, Drent M. Assessing health status and quality of life in idiopathic pulmonary fibrosis: which measure should be used? Respir Med 2000; 94: 273-278.

16. Martinez TY, Pereira CA, dos Santos ML, Ciconelli RM, Guimarães $\mathrm{SM}$, Martinez JA. Evaluation of the short-form 36-item questionnaire to measure health-related quality of life in patients with idiopathic pulmonary fibrosis. Chest 2000; 117: 1627-1632.

17. Chang JA, Curtis JR, Patrick DL, Raghu G. Assessment of healthrelated quality of life in patients with interstitial lung disease. Chest 1999; 116: 1175-1182.

18. Mahler DA, MacKowiak JI. Evaluation of the short-form 36-item questionnaire to measure health-related quality of life in patients with COPD. Chest 1995; 107: 1585-1589.

19. Wilson CB, Jones PW, O'Leary CJ, Cole PJ, Wilson R. Validation of the St. George's Respiratory Questionnaire in bronchiectasis. Am J Respir Crit Care Med 1997; 156: 536-541.

20. Mahler DA, Weinberg DH, Wells CK, Feinstein AR. The measurement of dyspnea. Contents, interobserver agreement, and physiologic correlates of two new clinical indexes. Chest 1984; 85: 751758.

21. Burdon JG, Juniper EF, Killian KJ, Hargreave FE, Campbell EJ. The perception of breathlessness in asthma. Am Rev Respir Dis 1982; 126: 825-828.

22. van der Molen T, Postma DS, Schreurs AJ, Bosveld HE, Sears MR Meyboom de JB. Discriminative aspects of two generic and two asthma-specific instruments: relation with symptoms, bronchodilator use and lung function in patients with mild asthma. Qual Life Res 1997; 6: 353-361. 
23. Ciconelli RM. Tradução para a língua portuguesa e validação do Medical Outcomes Study 36-Item Short-Form Health Survey (SF36). [Doctoral thesis]. São Paulo: Departamento de Clínica Médica, USP; 1997.

24. Jones PW. Measurement of health in asthma and chronic airways disease. Pharm Med 1992; 6: 13-22.

25. Guyatt GH, Sullivan MJ, Thompson PJ, Fallen EL, Pugsley SO, Taylor DW, et al. The 6-minute walk: a new measure of exercise capacity in patients with chronic heart failure. Can Med Assoc J 1985; 132: 919-923.

26. Bittner V, Weiner DH, Yusuf S, Rogers WJ, Mclntyre KM, Bangdiwala $\mathrm{SI}$, et al. Prediction of mortality and morbidity with a 6-minute walk test in patients with left ventricular dysfunction. SOLVD Investigators. JAMA 1993; 270: 1702-1707.

27. American Thoracic Society. Pulmonary rehabilitation-1999. Am J Respir Crit Care Med 1999; 159: 1666-1682.

28. Goldman HI, Becklake MR. Respiratory function tests; normal values at median altitudes and the prediction of normal results. Am Rev Tuberc 1959; 79: 457-467.

29. American Thoracic Society. Single-breath carbon monoxide diffusing capacity (transfer factor). Recommendations for a standard technique - 1995 update. Am J Respir Crit Care Med 1995; 152: 21852198.

30. Knudson RJ, Lebowitz MD, Holberg CJ, Burrows B. Changes in the normal maximal expiratory flow-volume curve with growth and aging. Am Rev Respir Dis 1983; 127: 725-734.

31. Gaensler EA, Smith AA. Attachment for automated single breath diffusing capacity measurement. Chest 1973; 63: 136-145.
32. Panos RJ, Mortenson RL, Niccoli SA, King TE Jr. Clinical deterioration in patients with idiopathic pulmonary fibrosis: causes and assessment. Am J Med 1990; 88: 396-404.

33. Swigris JJ, Gould MK, Wilson SR. Health-related quality of life among patients with idiopathic pulmonary fibrosis. Chest 2005; 127 : 284-294.

34. Clark M, Cooper B, Singh S, Cooper M, Carr A, Hubbard R. A survey of nocturnal hypoxaemia and health related quality of life in patients with cryptogenic fibrosing alveolitis. Thorax 2001; 56: 482-486.

35. Baddini Martinez JA, Martinez TY, Lovetro Galhardo FP, de Castro Pereira CA. Dyspnea scales as a measure of health-related quality of life in patients with idiopathic pulmonary fibrosis. Med Sci Monit 2002; 8: CR405-CR410.

36. de Vries J, Kessels BL, Drent M. Quality of life of idiopathic pulmonary fibrosis patients. Eur Respir J 2001; 17: 954-961.

37. Guyatt GH, Berman LB, Townsend M, Pugsley SO, Chambers LW. A measure of quality of life for clinical trials in chronic lung disease. Thorax 1987; 42: 773-778.

38. Flaherty KR, Martinez FJ. The role of pulmonary function testing in pulmonary fibrosis. Curr Opin Pulm Med 2000; 6: 404-410.

39. Turner-Warwick M, Burrows B, Johnson A. Cryptogenic fibrosing alveolitis: clinical features and their influence on survival. Thorax 1980; 35: 171-180.

40. Nishiyama O, Taniguchi H, Kondoh Y, Kimura T, Ogawa T, Watanabe $F$, et al. Health-related quality of life in patients with idiopathic pulmonary fibrosis. What is the main contributing factor? Respir Med 2005; 99: 408-414. 